\title{
LGBTQ Bullying: Translating Research to Action in Pediatrics
}

Valerie A. Earnshaw, PhD, a,b,c Sari L. Reisner, ScD, a,b,d,e Jaana Juvonen, PhD, ${ }^{f}$

Mark L. Hatzenbuehler, PhD, ${ }^{g}$ Jeff Perrotti, MA, CAS, ${ }^{h}$ Mark A. Schuster, MD, PhD ${ }^{a, b}$

Lesbian, gay, bisexual, transgender, and queer (LGBTQ) youth experience significant bullying that undermines their mental and physical health. National health organizations have called for the development of innovative strategies to address LGBTQ bullying. Pediatricians and other clinicians, medical and public health students, interdisciplinary researchers, government officials, school leaders, community members, parents, and youth from around the country came together at a national symposium entitled "LGBTQ Bullying: Translating Research to Action to Improve the Health of All Youth" in May 2016 to generate strategies to prevent LGBTQ bullying and meet the needs of LGBTQ youth experiencing bullying. This article describes key scientific findings on bullying, LGBTQ stigma, and LGBTQ bullying interventions that were shared at the symposium and provides recommendations for pediatricians to address LGBTQ bullying via clinical care, research, interventions, and policy. Symposium participants recommended that pediatricians engage in efforts to foster inclusive and affirming health care environments wherein LGBTQ youth feel comfortable discussing their identities and experiences, identify youth experiencing LGBTQ bullying, and prevent the negative health consequences of bullying among youth. Moreover, pediatricians can attend to how multiple identities (eg, sexual orientation, gender identity, race and/or ethnicity, disability, and others) shape youth experiences of bullying and expand intervention efforts to address LGBTQ bullying in health care settings. Pediatricians can further advocate for evidence-based, antibullying policies prohibiting bullying on the basis of sexual orientation and gender identity. Collaboration between pediatricians and diverse stakeholders can contribute to the development and implementation of lasting change in all forms of bullying, including LGBTQ bullying.

Bullying experienced during childhood and adolescence has far-reaching effects, undermining the mental and physical health of youth who are bullied. ${ }^{1,2}$ Recent research suggests that stigma-based bullying (or bullying associated with socially devalued identities, characteristics, and attributes [also referred to as bias-based bullying]) is both highly prevalent and more strongly associated with health problems than bullying in general. ${ }^{3}$
Lesbian, gay, bisexual, transgender, and queer (LGBTQ) youth, in particular, experience significant verbal bullying, physical bullying, and cyberbullying ${ }^{4-7}$ leading to physical injury, psychological distress, and even suicide. ${ }^{3,8-10}$ The prevalence and consequences of bullying among LGBTQ youth are increasingly well understood, yet successful efforts to address LGBTQ bullying are lagging. The American Academy of Pediatrics; the National Academies of Sciences,

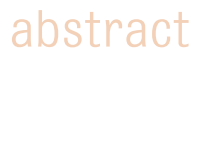

aDivision of General Pediatrics, Boston Children's Hospital, Boston, Massachusetts; ${ }^{b}$ Department of Pediatrics, Harvard Medical School, Boston, Massachusetts; ${ }^{d}$ Department of Epidemiology, Harvard T.H. Chan School of Public Health, Harvard University, Boston, Massachusetts; ${ }^{c}$ Department of Human Development and Family Sciences, University of Delaware, Newark, Delaware; ${ }^{e}$ The Fenway Institute, Fenway Health, Boston, Massachusetts; ${ }^{f}$ Department of Psychology, University of California, Los Angeles, Los Angeles,

California; ${ }^{g}$ Department of Sociomedical Sciences, Mailman School of Public Health, Columbia University, New York,

New York; and ${ }^{\text {hS }}$ afe Schools Program for LGBTQ Students, Massachusetts Department of Elementary and Secondary Education, Malden, Massachusetts

Dr Earnshaw was a member of the committee that organized the symposium on which the manuscript is based, presented at the symposium, and drafted and revised the manuscript; Dr Reisner was also a member of the symposium organizing committee, presented at the symposium, and contributed to the conception of the manuscript and its revision; Drs Juvonen, Hatzenbuehler, and Perrotti presented at the symposium and contributed to the conception of the manuscript and its revision; Dr Schuster chaired the symposium organizing committee, presented at the symposium, contributed to the conception of the manuscript and its revision, and supervised all aspects of this work; and all authors gave final approval of the manuscript as submitted and agreed to be accountable for all aspects of the work.

This work was presented in part at the symposium LGBTQ Bullying: Translating Research to Action to Improve the Health of All Youth; May 10, 2016; Boston, MA.

Dol: https://doi.org/10.1542/peds.2017-0432

Accepted for publication Jul 17, 2017

Address correspondence to Valerie A. Earnshaw, PhD, Division of General Pediatrics, Boston Children's Hospital, 130 Enders Building, 300 Longwood Ave, Boston, MA 02115. E-mail: valerie. earnshaw@gmail.com

To cite: Earnshaw VA, Reisner SL, Juvonen J, et al LGBTQ Bullying: Translating Research to Action in Pediatrics. Pediatrics. 2017;140(4):e20170432 
Engineering, and Medicine; and the American Public Health Association have all called for the development of innovative strategies to address LGBTQ bullying.111,12 Greater dialogue among pediatricians and other types of clinicians, medical and public health students, interdisciplinary researchers, government officials, school leaders, community members, parents, and youth is needed to generate strategies to prevent LGBTQ bullying and meet the needs of LGBTQ youth experiencing bullying.

To facilitate this dialogue and respond to calls from national health organizations, the Harvard Clinical and Translational Science Center's Health Disparities Research Program; Boston Children's Hospital; the Williams Institute at the University of California, Los Angeles; and Harvard Medical School sponsored a symposium entitled "LGBTQ Bullying: Translating Research to Action to Improve the Health of All Youth" in May 2016 (see the Appendix for the symposium agenda). The symposium brought together multidisciplinary stakeholders from around the country and sparked conversation about how best to reduce bullying and meet the needs of LGBTQ youth experiencing bullying. Herein, we summarize scientific findings presented at the symposium and share recommendations generated by symposium participants that are relevant to pediatricians who engage in clinical care, research, intervention, and policy advocacy.

\section{CURRENT STATE OF THE RESEARCH}

Research on bullying, peer victimization, and LGBTQ stigma has substantially increased over the past 2 decades yet has remained largely siloed by academic and professional disciplines. ${ }^{2}$ Symposium participants described key findings from these areas of research as well as findings that have begun to merge these silos.
Participants further outlined recent developments in interventions to address LGBTQ bullying, which provide a critical foundation for future work. In summarizing this research, we employ acronyms that best represent the samples studied (eg, LGBQ for lesbian, gay, bisexual, and queer youth; LGB for lesbian, gay, and bisexual youth).

\section{Bullying}

Nationally representative data suggest that $\sim 20 \%$ of youth in the United States report being bullied at school.1,13,14 The US Centers for Disease Control and Prevention and the Department of Education provide the following definition of bullying, which states that: "Bullying is any unwanted aggressive behavior(s) by another youth or group of youths who are not siblings or current dating partners that involves an observed or perceived power imbalance and is repeated multiple times or is highly likely to be repeated. Bullying may inflict harm or distress on the targeted youth including physical, psychological, or educational harm."15

As described by Juvonen and Graham, ${ }^{2}$ bullying is a strategic behavior used by youth to gain and maintain positions of social power or popularity within their peer groups. Bullies often have inflated self-views and are driven to exert control over other youth. Moreover, bullying frequently serves a social function of defining and enforcing social norms (eg, heterosexual relationships and traditional, binary gender roles) within peer groups.

Certain youth are more likely to be targeted by bullying, including youth who are less socially connected and youth who belong to stigmatized groups, such as LGBTQ youth. Bullying significantly increases the risk of psychological and physical harm. Youth who are repeatedly bullied by peers may internalize their experiences by blaming themselves ${ }^{16}$ and in turn develop anxiety and depressive symptoms. ${ }^{2,17}$ They may also have psychosomatic problems, such as stomachaches and headaches, ${ }^{18,19}$ as well as physical injuries as a result of bullying. ${ }^{20}$ Youth may also externalize their experiences of bullying, feeling anger and frustration and sometimes mistreating other youth. ${ }^{21}$ Accumulating evidence further suggests that bullying alters biological functioning among targeted youth (eg, by dysregulating hypothalamicpituitary-adrenal axis functioning and eroding telomere length), with farreaching health consequences. ${ }^{22}$

\section{LGBTQ Stigma}

Bullying of LGBTQ youth stems from stigma, which is the social devaluation and discrediting that occurs when several processes co-occur and are reinforced by power, including labeling, stereotyping, separation, status loss, and discrimination. ${ }^{23}$ LGBTQ stigma is manifested at the structural (eg, laws and policies), interpersonal (eg, discrimination), and intrapersonal (eg, internalized or self-stigma) levels ${ }^{24}$ and serves the function of enforcing social norms of heterosexuality and traditional, binary gender roles. ${ }^{25}$ LGBTQ bullying is an interpersonal manifestation of LGBTQ stigma ${ }^{24}$ and can be conceptualized as a form of LGBTQ discrimination.

\section{LGBTQ youth report experiencing} more bullying than their non-LGBTQ peers. According to data from the nationally representative Youth Risk Behavior Surveillance System, 18.8\% of heterosexual students reported being bullied at school in comparison with $34.2 \%$ of LGB students from 2014 to $2015 .^{26}$ Although nationally representative data are not available for gender minority youth (the Youth Risk Behavioral Surveillance System does not include items measuring gender identity), evidence suggests that they also experience 
more bullying than their peers. ${ }^{6}$ As with non-LGBTQ youth, bullying undermines the well-being of LGBTQ youth. However, emerging evidence suggests that stigma-based bullying, including bullying that is motivated by actual or perceived sexual orientation, is associated with worse health outcomes than nonstigma-based bullying. ${ }^{3}$ Moreover, the harmful effects of LGBTQ bullying last into adulthood. ${ }^{27}$

The social context surrounding youth shapes the prevalence and outcomes of LGBTQ bullying. For example, LGBQ girls in schools with more LGBQ students experience less emotional distress in response to bullying than those in schools with fewer LGBQ students. ${ }^{28}$ Sexual minority youth living in neighborhoods where fewer LGBTQ-targeted assault hate crimes occur are less likely to be bullied than those living in neighborhoods with a greater prevalence of such crimes. ${ }^{29}$ Furthermore, LG youth who live in counties where a greater proportion of school districts have antibullying policies that include sexual orientation have a lower risk of suicide attempts than those in counties with fewer districts with these policy protections. ${ }^{30}$ Notably, the presence of any antibullying policy does not protect against the risk of suicide attempt for LG youth; only antibullying policies that explicitly include sexual orientation are associated with lower risk of suicide attempts among LG students. ${ }^{30}$ It is possible that antibullying policies that provide enumerated protections for sexual minority students already reflect a school environment that promotes diversity and inclusion; it is also possible that these policies help to further shape inclusive school environments. Future research is needed to test these hypotheses.

\section{Bullying Interventions}

The majority of bullying interventions, including LGBTQ bullying interventions, occur in school settings. It is important for physicians to know about such programs so that they are informed when parents and schools seek their input on how to address bullying in schools. Interventions that have been described in the peerreviewed literature include universal prevention programs in school settings that involve all students ${ }^{31-34}$ and teachers ${ }^{35-38}$ or students, teachers, and staff ${ }^{39}$ and aim to prevent LGBTQ bullying as well as indicated preventive programs to intervene among youth who were already involved in LGBTQ bullying. ${ }^{40}$ Interventions have employed a wide range of strategies, including instruction, discussion, activities, and theater for students; professional development for teachers; and/ or policy development for whole schools. The Massachusetts Safe Schools Program for Lesbian, Gay, Bisexual, Transgender, Queer and Questioning (LGBTQ) Students, which is a joint initiative between the Massachusetts Department of Elementary and Secondary Education and the Massachusetts Commission on LGBTQ Youth, represents an example of a universal program that incorporates many of these strategies. ${ }^{39,41,42}$

Studies suggest some promise for school-based LGBTQ bullying interventions. For example, they have been associated with reductions in LGBTQ bullying, greater commitment to intervening in LGBTQ bullying, greater knowledge about LGBTQ bullying, greater ability to empathize with LGBTQ students, and better school climate for LGBTQ students. ${ }^{31-40}$ However, it is important to note that most of these interventions have not been evaluated with randomized controlled trials or in large-scale settings (eg, entire school districts). More work is needed to rigorously evaluate the efficacy and generalizability of these interventions. Moreover, additional work is needed to evaluate whether popular interventions designed to address bullying in general (eg, Olweus Bullying Prevention Program ${ }^{43}$ and $\mathrm{KiVa}^{44}$ ) reduce LGBTQ bullying specifically. To date, evaluations of these interventions have not included measures of LGBTQ bullying, and so their effects on LGBTQ bullying remain largely unknown. ${ }^{1}$

Additionally, some evidence supports positive benefits of Gender and Sexuality Alliances (GSAs, also known as Gay-Straight Alliances) for students. GSAs are generally schoolbased clubs that provide comfortable settings for LGBTQ students and their peers to socialize and promote inclusive school climates. ${ }^{4,45}$ Research is mixed regarding whether LGBTQ students in schools with GSAs experience less bullying than students in schools without them. ${ }^{4,46}$ Yet, studies suggest that GSAs are associated with positive well-being among LGBTQ students. LGBTQ students in schools with GSAs report engaging in fewer health risk behaviors (eg, substance use, sex while using substances, and suicide attempts) and have more positive psychosocial well-being and educational attainment as young adults compared with LGBTQ students in schools without them. ${ }^{46,47}$ GSAs also provide important opportunities to foster social integration between LGBTQ youth and their non-LGBTQ peers in ways that promote well-being among LGBTQ students. ${ }^{4,45}$ At the same time, existing research on GSAs has some limitations, including a reliance on cross-sectional studies, convenience samples, and designs that do not allow for the exploration of plausible alternative explanations (eg, selection effects). Therefore, it is possible that schools with more positive climates are more likely to have GSAs. 
TABLE 1 Key Recommendations for Future Directions

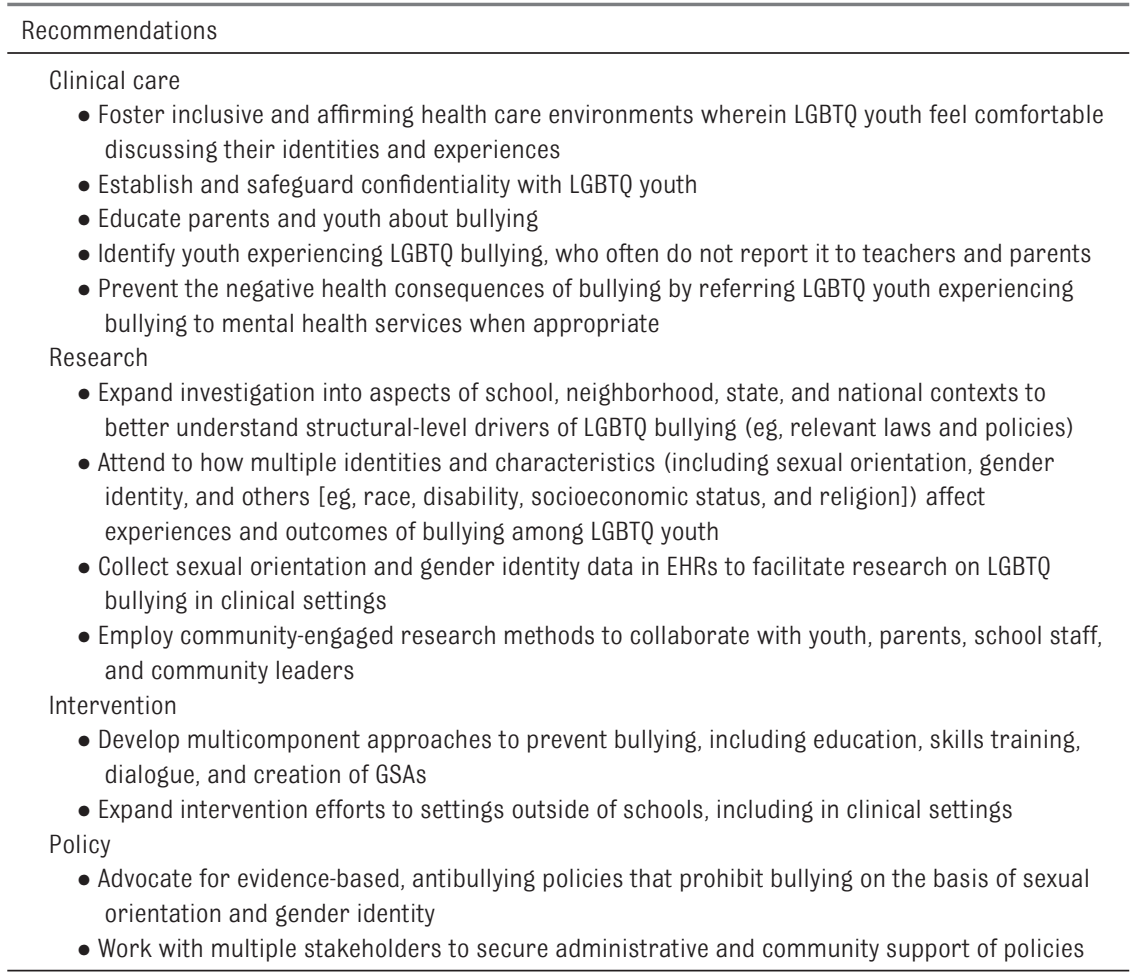

Significant legal, policy, and cultural barriers sometimes inhibit the implementation of LGBTQ bullying interventions and GSAs in schools. For example, 8 states currently have laws that ban school personnel from discussing homosexuality in school. ${ }^{48,49}$ Pediatric health care settings may therefore represent important opportunities for intervention to address LGBTQ bullying to improve the health of targeted youth. Yet, there are currently no known peerreviewed published interventions that address LGBTQ bullying in health care settings.

\section{FUTURE DIRECTIONS}

Symposium participants (including speakers, panelists, and audience members) generated recommendations for future directions in clinical care, research, intervention, and policy to address LGBTQ bullying (summarized in Table 1). Herein, we focus on recommendations for pediatricians. Building and strengthening collaborations between pediatricians and other stakeholders, including other clinicians, researchers, government officials, school personnel, community leaders, parents, and students, was a recurring theme.

\section{Clinical Care}

Pediatricians and other clinicians who care for children can play a unique and important role in addressing all forms of bullying, including LGBTQ bullying, as a means of promoting the well-being of youth. ${ }^{50}$ Pediatricians can foster inclusive and affirming health care environments wherein LGBTQ youth feel comfortable discussing their identity and experiences, including those involving bullying. ${ }^{51}$ Cues signaling inclusivity can be integrated into the clinical environment. These could include signs, stickers, and handouts that are provided by the Safe Space Kit from the Gay, Lesbian and Straight Education Network (GLSEN) ${ }^{52}$ as well as health brochures and reading materials that are tailored to the needs of LGBTQ youth (eg, brochures on reproductive health that do not presume heterosexuality). ${ }^{51}$ Signs encouraging individuals to use the bathroom that matches their gender identity rather than biologic sex can be affirming for transgender youth. ${ }^{51}$ Pediatricians and clinic staff can participate in campaigns to address LGBTQ bullying and support LGBTQ youth, including antibullying Spirit Day (organized by GLAAD, formerly known as the Gay and Lesbian Alliance Against Defamation) ${ }^{53}$ and Ally Week (organized by GLSEN). ${ }^{54}$

Pediatricians may also signal inclusivity when interacting with individual youth. Pediatricians can use language that builds trusting relationships, such as avoiding questions that assume the gender of individual's partners and asking which gender pronouns are preferred (eg, he and him, she and her, they and them). ${ }^{51}$ Pediatricians can establish and safeguard confidentiality to the best of their ability, including by protecting information about sexual orientation and gender identity, given that some youth may have not disclosed this information to other adults. ${ }^{51}$ If youth are accompanied by parents, pediatricians can aim to spend 1-on-1 time with youth to ask about issues that they may not feel comfortable discussing in front of their parents, including experiences of bullying. ${ }^{51}$

Pediatricians can educate parents and youth about how to recognize and respond to bullying. Parents who are supportive have the potential to protect youth from the negative effects of LGBTQ bullying, and LGBTQ youth with accepting parents have better well-being than LGBTQ youth without accepting parents. ${ }^{55}$, 56 Pediatricians may promote this support and acceptance by providing encouragement as well as educational and other resources to parents of LGBTQ children. Resources to support parents are 
available from the Family Acceptance Project and PFLAG (formerly known as Parents, Families, and Friends of Lesbians and Gays). ${ }^{57,58}$

Pediatricians can also identify youth who are targets of LGBTQ bullying. ${ }^{50}$ Many LGBT youth who are bullied do not tell adults, including parents and teachers, because they worry about how these adults will react. ${ }^{4}$ Youth have reported that they would feel comfortable talking with their physicians about being LGB if their physicians were to ask them about it. ${ }^{59}$ Similarly, youth may feel comfortable talking with their physicians about their experiences of LGBTQ bullying if their physicians were to ask them about it.

Pediatricians can ask youth about their experiences of bullying and can look for symptoms indicating that youth have been bullied (eg, physical injury and psychosomatic issues).

Pediatricians can play a role in preventing the negative health consequences of bullying among youth who are bullied. ${ }^{50}$ Pediatricians can advise youth on how to respond to bullying in ways that can often promote their safety, such as by staying calm, leaving the situation when able, and informing an adult. ${ }^{60}$ They can also help youth identify supportive adults at school to whom they can turn when bullied (eg, school personnel who display safe zone stickers, teachers who use inclusive language and don't tolerate anti-LGBTQ language, and GSA advisors). Some youth who are bullied experience feelings of helplessness, shame, and isolation. Pediatricians should refer youth experiencing clinically significant depressive, anxiety, or other psychological symptoms to mental health services. Early intervention may help to buffer youth from the negative long-term consequences of bullying. The American Academy of Pediatrics, the American Medical Association, and the US Department of Health and Human Services have produced resources that can help pediatricians prevent and respond to bullying. ${ }^{60-62}$ Pediatricians may also seek to build relationships with school nurses and counselors, who may be the first health care professionals to interact with students after incidents of bullying, ${ }^{1}$ to contribute to local bullying prevention and intervention efforts.

\section{Research}

Clinician researchers are well positioned to address critical gaps in the current landscape of LGBTQ bullying research. To date, most research on bullying has occurred at the individual level within school settings. Pediatricians and other clinicians, who are often trained to think broadly about how factors at multiple socioecological levels and in multiple settings contribute to health outcomes, are well suited to engage in multilevel research that is inclusive of contexts beyond schools. Emerging evidence suggests that the social context surrounding youth (eg, the composition of neighborhoods and policies) affects the prevalence and outcomes of bullying, including LGBTQ bullying specifically. ${ }^{28-30}$ Clinician researchers should expand investigation into aspects of neighborhood, state, and national contexts (eg, policies, trainings, and social norms) to better understand structural-level drivers of LGBTQ bullying. Given that bullying also occurs outside of school settings (eg, camps and clubs), clinician researchers should study it in settings other than schools to more fully characterize the experiences of bullying among LGBTQ youth. This research may also facilitate the inclusion of LGBTQ youth who have high rates of absenteeism or who have dropped out of school, perhaps because of bullying.

Attending to the multiple identities and characteristics of LGBTQ youth may provide a more nuanced understanding of how bullying affects youth mental, behavioral, and physical health as well as strategies to address bullying. Research typically examines 1 type of bullying in isolation, such as bullying associated with sexual orientation, gender identity, or another characteristic (eg, race, disability, socioeconomic status, or religion). Yet, LGBTQ youth live with sexual orientations, gender identities, and other characteristics simultaneously, all of which may shape their experiences of and vulnerability to bullying. An intersectional approach, which recognizes that individuals live with multiple characteristics and identities, ${ }^{63-65}$ can be incorporated into research as a framework for studying how multiple characteristics and identities affect the experiences and outcomes of bullying among LGBTQ youth.

Enhancing ongoing research efforts may expand understanding of LGBTQ bullying. Electronic health records (EHRs) are an important and underused source of data for investigating bullying and health among LGBTQ youth and can inform future clinical care and research. Standardized collection of sexual orientation and gender identity data in EHRs is recommended. ${ }^{66-69}$ There are multiple ways to collect sexual orientation and gender identity data in clinical settings. Registration and other intake processes can capture information about sexual orientation and gender identity as part of demographics alongside information about race, sex, and date of birth. Youth may self-disclose to pediatricians as a response to openended questions, such as, "Tell me about yourself." Youth can also be asked about their sexual orientation and gender identity when obtaining a history. Gathering sexual orientation and gender identity data in clinical settings on a periodic basis can allow clinician researchers to measure and track LGBTQ youth outcomes over time, including experiences 
of bullying. These data may lead to improved understanding of the prevalence, developmental course, and adverse health outcomes associated with bullying among LGBTQ youth. In addition, such data can improve clinical care delivery and intervention research. Providers who are informed of youth sexual orientation and gender identity can better provide care that meets the specific needs of LGBTQ youth, including by screening for bullying.

Employing community-engaged research methods is key to improving the quality of research on bullying and ensuring that research is used to effectively address LGBTQ bullying. Clinician researchers should engage with multiple community stakeholders (such as youth, parents, school staff, community leaders, and advocates) to ensure that their research is informed by diverse perspectives and, when appropriate, is responsive to community needs. For example, input from youth and parents is needed to inform EHR data collection of sexual orientation and gender identity within clinical care settings to ensure the acceptability of questions asked and address any concerns about confidentiality and privacy. Pediatricians can collaborate with school health professionals (eg, nurses) who serve LGBTQ youth in school settings to consider research linking multidisciplinary providers both inside and outside of schools. Such community involvement has the potential to lead to creative solutions for addressing LGBTQ bullying. Moreover, clinician researchers should work to disseminate their findings broadly to enhance understanding of LGBTQ bullying and contribute to intervention strategies to address LGBTQ bullying.

\section{Intervention}

Pediatricians can contribute to efforts to strengthen school-based LGBTQ bullying interventions as well as expand LGBTQ interventions beyond school settings. Pediatricians, including those who work with schools, can advocate for the development of multicomponent approaches to change norms that facilitate LGBTQ bullying in schools. For example, schools can implement LGBTQ-inclusive curricula by using resources from organizations that incorporate LGBTQ history and themes into lessons. ${ }^{70}$ Education and skills training for youth and adults can help individuals recognize bullying and gain skills to intervene in bullying. Trainings should build awareness of transgender and nonbinary gender identities and encourage support for students who transition and/or want to participate in clubs or use facilities consistent with their gender identity. Intervention efforts are also needed for youth who are questioning their sexual orientation or gender identity; this group may require different intervention approaches relative to their self-identified LGBTQ peers. ${ }^{71}$ Moreover, pediatricians can advocate for interventions to address LGBTQ bullying outside of school settings, such as in clinical, recreational (eg, camps and nonschool-based sport organizations), volunteer, and other settings.

Interventions to address LGBTQ bullying have the potential to improve outcomes for all youth, including those who identify as LGBTQ, are not LGBTQ but experience LGBTQ bullying, ${ }^{72}$ are bullied because of other stigmatized characteristics (eg, race, disability, socioeconomic status, religion, and weight), and/or witness LGBTQ bullying as bystanders. Some emerging experimental evidence suggests that interventions designed to signal inclusivity toward members of 1 stigmatized group (eg, LGBTQ youth) may lead members of other stigmatized groups to feel safe as well (eg, racial minority youth). ${ }^{73}$ Therefore, interventions designed to promote LGBTQ inclusivity may enhance feelings of safety and belonging among all youth.

Policy

At the federal and state levels, more research is needed on the effectiveness of specific components of antibullying policies (such as enumerated policies that prohibit bullying on the basis of sexual orientation and gender identity and defining consequences for individuals who engage in LGBTQ bullying) in reducing bullying behaviors. Although there is currently a dearth of research on the efficacy of antibullying policies in reducing bullying (both general forms of bullying and bias-based bullying), ${ }^{1}$ pediatricians have important roles to play in contributing to additional research in this area and in advocating for policies once an evidence base has accumulated. In addition, pediatricians can play a role in repealing or preventing laws that are already known to be harmful, such as those banning school personnel from discussing homosexuality in school. ${ }^{49}$ The involvement of multiple stakeholders, including pediatricians, is therefore critical for developing and implementing policies to address bullying. ${ }^{39}$

\section{CONCLUSIONS}

Pediatricians have an opportunity to play a leading role in addressing LGBTQ bullying via clinical care, research, intervention, and policy. Collaborations among pediatricians and other types of clinicians, medical and public health students, interdisciplinary researchers, government officials, school leaders, community members, parents, and youth are needed to develop, implement, and sustain lasting change in all forms of bullying, including LGBTQ bullying. Such change is needed to promote the health of LGBTQ youth and adults. 


\section{APPENDIX: SYMPOSIUM AGENDA}

\section{Opening Keynote}

- Welcome by Mark A. Schuster, MD, PhD, of Boston Children's Hospital and Harvard Medical School;

- Introduction by Wayne Maines, EdD, father of Nicole Maines; and

- Keynote address by Nicole A. Maines, of "Becoming Nicole" by Amy Ellis Nutt.

\section{Stigma-Based Bullying}

- Overview by Jaana Juvonen, PhD, of the University of California, Los Angeles; and

- Panel discussion moderated by Michelle A. Williams, ScD, of the Harvard T.H. Chan School of Public Health and including the following:

o Jaana Juvonen, $\mathrm{PhD}$, of the University of California, Los Angeles;

○ Wayne Maines, EdD, father of Nicole Maines;

o Rebecca M. Puhl, PhD, of the University of Connecticut; and

o David R. Williams, PhD, MPH, of the Harvard T.H. Chan School of Public Health.

\section{LGBTQ Bullying and Discrimination}

- Overview by Mark L.

Hatzenbuehler, PhD, of the Columbia University Mailman School of Public Health; and

- Panel discussion moderated by S. Bryn Austin, ScD, of Boston Children's Hospital, Harvard Medical School, and the Harvard T.H. Chan School of Public Health and including the following:

o Cameron Hardie, of Boston Latin Academy; o Mark L. Hatzenbuehler, PhD, of the Columbia University Mailman School of Public Health;

o Ilan H. Meyer, PhD, of the Williams Institute of the University of California, Los Angeles, School of Law;

o Sari L. Reisner, ScD, of Boston Children's Hospital, Harvard Medical School, and the Harvard T.H. Chan School of Public Health; and

o ViQuan Smith, of True Colors.

\section{Lunch Breakout Sessions}

- Small group discussions to share ideas about how to address LGBTQ bullying with report back led by Jeff Perrotti, MA, CAS, of the Safe Schools Program for LGBTQ Students of the Massachusetts Department of Elementary and Secondary Education, and groups led by the following:

o Stewart L. Adelson, MD, of the Columbia University College of Physicians and Surgeons;

○ Jodie Elgee, BSW, of Boston Public Schools;

- Allegra R. Gordon, ScD, of Boston Children's Hospital and Harvard Medical School;

o Carly E. Guss, MD, of Boston Children's Hospital and Harvard Medical School;

- Jessica Halem, MBA, of Harvard Medical School;

o Sabra L. Katz-Wise, PhD, of Boston Children's Hospital and Harvard Medical School;

o Robert L. Kitts, MD, of Boston Children's Hospital and Harvard Medical School; and
- Rodney VanDerwarker, MPH, of The Fenway Institute.

\section{Interventions}

- Overview by Valerie A. Earnshaw, $\mathrm{PhD}$, of Boston Children's Hospital and Harvard Medical School; and

- Panel discussion moderated by Gary Bailey, DHL, MSW, ACSW, of the Simmons School of Social Work and the Simmons School of Nursing and Health Sciences and including the following:

○ Dorothy L. Espelage, PhD, of the University of Illinois at Urbana-Champaign

o Sara F. Forman, MD, of Boston Children's Hospital and Harvard Medical School;

o Polly Y. Gipson, PhD, of the University of Michigan;

o Amalio Nieves, MS, of Boston Public Schools; and

○ V. Paul Poteat, PhD, of Boston College.

\section{Closing Remarks}

- Introduction by Mark A. Schuster, $\mathrm{MD}, \mathrm{PhD}$, of Boston Children's Hospital and Harvard Medical School; and

- Takeaways and next steps by Eliza S. Byard, PhD, of GLSEN.

\section{ABBREVIATIONS}

EHR: electronic health record GLSEN: Gay, Lesbian and Straight Education Network

GSA: Gender and Sexuality Alliance/Gay-Straight Alliance

LGBTQ: lesbian, gay, bisexual, transgender, and queer

PEDIATRICS (ISSN Numbers: Print, 0031-4005; Online, 1098-4275)

Copyright (C) 2017 by the American Academy of Pediatrics

FINANCIAL DISCLOSURE: The authors have indicated they have no financial relationships relevant to this article to disclose.

FUNDING: Funded by a grant from the National Institutes of Health (NIH) to the Harvard Clinical and Translational Science Center (NIH UL1 TR001102) and the Williams Institute at the University of California, Los Angeles. Funded by the National Institutes of Health (NIH).

POTENTIAL CONFLICT OF INTEREST: The authors have indicated they have no potential conflicts of interest to disclose. 


\section{REFERENCES}

1. National Academies of Sciences, Engineering, and Medicine. Preventing Bullying Through Science, Policy, and Practice. Washington, DC: The National Academies Press; 2016

2. Juvonen J, Graham S. Bullying in schools: the power of bullies and the plight of victims. Annu Rev Psychol. 2014;65:159-185

3. Russell ST, Sinclair K0, Poteat VP, Koenig BW. Adolescent health and harassment based on discriminatory bias. Am J Public Health. 2012;102(3):493-495

4. Kosciw JG, Greytak EA, Giga NM, Villenas C, Danischewski DJ. The 2015 National School Climate Survey: The Experiences of Lesbian, Gay, Bisexual, Transgender, and Queer Youth in Our Nation's Schools. New York, NY: GLSEN; 2016

5. Schuster MA, Bogart LM, Elliott MN, et al. A longitudinal study of bullying of sexual-minority youth. N Engl J Med. 2015;372(19):1872-1874

6. Reisner SL, Greytak EA, Parsons JT, Ybarra ML. Gender minority social stress in adolescence: disparities in adolescent bullying and substance use by gender identity. J Sex Res. 2015;52(3):243-256

7. Russell ST, Everett BG, Rosario M, Birkett M. Indicators of victimization and sexual orientation among adolescents: analyses from Youth Risk Behavior Surveys. Am J Public Health. 2014;104 (2) :255-261

8. Friedman MS, Koeske GF, Silvestre AJ, Korr WS, Sites EW. The impact of gender-role nonconforming behavior, bullying, and social support on suicidality among gay male youth. J Adolesc Health. 2006;38(5):621-623

9. Russell ST, Joyner K. Adolescent sexual orientation and suicide risk: evidence from a national study. Am J Public Health. 2001;91(8):1276-1281

10. Li MJ, Distefano A, Mouttapa M, Gill JK. Bias-motivated bullying and psychosocial problems: implications for HIV risk behaviors among young men who have sex with men. AIDS Care. 2014;26(2):246-256

11. American Public Health Association. Reduction of Bullying to Address Health
Disparities Among LGBT Youth. Policy Statement, 20142. Washington, DC: American Public Health Association; 2014

12. Committee on Injury, Violence, and Poison Prevention. Policy statementrole of the pediatrician in youth violence prevention. Pediatrics. 2009;124(1):393-402

13. US Department of Education. Student Reports of Bullying and Cyber-Bullying: Results From the 2013 School Crime Supplement to the National Crime Victimization Survey. Washington, DC: US Department of Education; 2015

14. Kann L, Kinchen S, Shanklin SL, et al; Centers for Disease Control and Prevention (CDC). Youth risk behavior surveillance-United States, 2013. MMWR Suppl. 2014;63(4):1-168

15. Gladden RM, Vivolo-Kantor AM, Hamburger ME, Lumpkin CD. Bullying Surveillance Among Youths: Uniform Definitions for Public Health and Recommended Data Elements, Version 1.0. Atlanta, GA: National Center for Injury Prevention and Control, Centers for Disease Control and Prevention, and U.S. Department of Education; 2014

16. Graham S, Juvonen J. Self-blame and peer victimization in middle school: an attributional analysis. Dev Psychol. 1998;34(3):587-599

17. Hawker DS, Boulton MJ. Twenty years' research on peer victimization and psychosocial maladjustment: a metaanalytic review of cross-sectional studies. J Child Psychol Psychiatry. 2000;41(4):441-455

18. Gini G, Pozzoli T. Bullied children and psychosomatic problems: a meta-analysis. Pediatrics. 2013;132(4):720-729

19. Fekkes M, Pijpers FI, Fredriks AM, Vogels T, Verloove-Vanhorick SP. Do bullied children get ill, or do ill children get bullied? A prospective cohort study on the relationship between bullying and healthrelated symptoms. Pediatrics. 2006;117(5):1568-1574

20. Wang J, lannotti RJ, Luk JW, Nansel TR. Co-occurrence of victimization from five subtypes of bullying: physical, verbal, social exclusion, spreading rumors, and cyber. J Pediatr Psychol. 2010;35(10):1103-1112

21. Nansel TR, Overpeck M, Pilla RS, Ruan WJ, Simons-Morton B, Scheidt P. Bullying behaviors among US youth: prevalence and association with psychosocial adjustment. JAMA. 2001;285(16):2094-2100

22. Vaillancourt T, Hymel S, McDougall P. The biological underpinnings of peer victimization: understanding why and how the effects of bullying can last a lifetime. Theory Pract 2013;52(4):241-248

23. Link BG, Phelan JC. Conceptualizing stigma. Annu Rev Sociol. 2001;27(1):363-385

24. Hatzenbuehler ML, Link BG. Introduction to the special issue on structural stigma and health. Soc Sci Med. 2014;103:1-6

25. Phelan JC, Link BG, Dovidio JF. Stigma and prejudice: one animal or two? Soc Sci Med. 2008;67 (3):358-367

26. Kann L, Olsen EOM, McManus T, et al. Sexual identity, sex of sexual contacts, and health-related behaviors among students in grades 9-12 - United States and selected sites, 2015. MMWR Surveill Summ. 2016;65(9):1-202

27. Birkett M, Newcomb ME, Mustanski B. Does it get better? A longitudinal analysis of psychological distress and victimization in lesbian, gay, bisexual, transgender, and questioning youth. $J$ Adolesc Health. 2015;56(3):280-285

28. Eisenberg ME, McMorris BJ, Gower AL, Chatterjee D. Bullying victimization and emotional distress: is there strength in numbers for vulnerable youth? J Psychosom Res. 2016;86:13-19

29. Hatzenbuehler ML, Duncan D, Johnson R. Neighborhood-level LGBT hate crimes and bullying among sexual minority youths: a geospatial analysis. Violence Vict. 2015;30(4):663-675

30. Hatzenbuehler ML, Keyes KM. Inclusive anti-bullying policies and reduced risk of suicide attempts in lesbian and gay youth. J Adolesc Health. 2013;53 (suppl 1):S21-S26

31. Wernick LJ, Dessel AB, Kulick A, Graham LF. LGBTQQ youth creating change: developing allies against 
bullying through performance and dialogue. Child Youth Serv Rev. 2013;35(9):1576-1586

32. Lucassen MF, Burford J. Educating for diversity: an evaluation of a sexuality diversity workshop to address secondary school bullying. Australas Psychiatry. 2015;23(5):544-549

33. Espelage DL, Low S, Polanin JR, Brown EC. Clinical trial of Second Step (C) middle-school program: impact on aggression \& victimization. J Appl Dev Psychol. 2015;37:52-63

34. Mattey E, McCloughan LJ, Hanrahan SJ. Anti-vilification programs in adolescent sport. J Sport Psychol Action. 2014;5(3):135-146

35. DePalma R, Atkinson E. 'No outsiders': moving beyond a discourse of tolerance to challenge heteronormativity in primary schools. Br Educ Res J. 2009;35(6):837-855

36. Dessel AB. Effects of intergroup dialogue: public school teachers and sexual orientation prejudice. Small Group Res. 2010;41(5):556-592

37. Taylor CG. A human rights approach to stopping homophobic bullying in schools. J Gay Lesbian Soc Serv. 2008;19(3-4):157-172

38. Payne E, Smith M. Reduction of stigma in schools: an evaluation of the first three years. Issues Teach Educ. 2010;19(2):11-36

39. Szalacha LA. Safer sexual diversity climates: lessons learned from an evaluation of Massachusetts safe schools program for gay and lesbian students. Am J Educ. 2003;110(1):58-88

40. Robertson ET. Promoting the acceptance of sexual diversity in a class of fifth grade boys. J LGBT Youth. 2008;5(1):15-26

41. Griffin P, Ouellett ML. Going beyond gay-straight alliances to make schools safe for lesbian, gay, bisexual, and transgender students. Policy J Inst Gay Lesbian Strategic Stud. 2002;6(1):1-7

42. Perrotti J, Westheimer K. When the Drama Club is Not Enough: Lessons From the Safe Schools Program for Gay and Lesbian Students. Boston, MA: Beacon Press; 2002

43. Olweus D. Bullying at School: What We Know and What We Can Do. Oxford, UK: Blackwell Publishing; 1993
44. Kärnä A, Voeten M, Little TD, Poskiparta E, Kaljonen A, Salmivalli C. A large-scale evaluation of the KiVa antibullying program: grades 4-6. Child Dev. 2011;82(1):311-330

45. GLSEN. Gay-straight alliances. Available at: www.glsen.org/participate/studentaction/gsa. Accessed December 13, 2016

46. Poteat VP, Sinclair K0, DiGiovanni CD, Koenig BW, Russell ST. Gay-straight alliances are associated with student health: a multischool comparison of LGBTQ and heterosexual youth. J Res Adolesc. 2013;23(2):319-330

47. Toomey RB, Ryan C, Diaz RM, Russell ST. High school gay-straight alliances (GSAs) and young adult well-being: an examination of GSA presence, participation, and perceived effectiveness. Appl Dev Sci. 2011;15(4):175-185

48. Meyer IH, Bayer R. School-based gay-affirmative interventions: first amendment and ethical concerns. Am J Public Health. 2013;103(10):1764-1771

49. GLSEN. "No promo homo" laws. Available at: www.glsen.org/learn/ policy/issues/nopromohomo. Accessed December 23, 2016

50. Earnshaw VA, Bogart LM, Poteat VP, Reisner SL, Schuster MA. Bullying among lesbian, gay, bisexual, and transgender youth. Pediatr Clin North Am. 2016;63 (6):999-1010

51. Hadland SE, Yehia BR, Makadon HJ. Caring for lesbian, gay, bisexual, transgender, and questioning youth in inclusive and affirmative environments. Pediatr Clin North Am. 2016;63(6):955-969

52. GLSEN. GLSEN's safe space kit: be an ALLY to LGBT youth. Available at: www.ǵlsen.org/safespace. Accessed November 7, 2016

53. GLAAD. \#SPIRITDAY: Take a stand against bullying. Available at: www. glaad.org/spiritday. Accessed November 7, 2016

54. GLSEN. About Ally Week. Available at: www.glsen.org/allyweek/about. Accessed November 7, 2016

55. Ryan C, Russell ST, Huebner D, Diaz $\mathrm{R}$, Sanchez J. Family acceptance in adolescence and the health of LGBT young adults. J Child Adolesc Psychiatr Nurs. 2010;23 (4):205-213

56. Poteat VP, Mereish EH, Digiovanni $C D$, Koenig BW. The effects of general and homophobic victimization on adolescents' psychosocial and educational concerns: the importance of intersecting identities and parent support. J Couns Psychol. 2011;58(4):597-609

57. Parents, Families, and Friends of Lesbians And Gays. Available at: https://www.pflag.org/. Accessed January 24, 2017

58. San Francisco State University. Family Acceptance Project. Available at: https://familyproject.sfsu.edu/. Accessed January 24, 2017

59. Meckler GD, Elliott MN, Kanouse DE, Beals KP, Schuster MA. Nondisclosure of sexual orientation to a physician among a sample of gay, lesbian, and bisexual youth. Arch Pediatr Adolesc Med. 2006;160(12):1248-1254

60. StopBullying.gov. Get help now. Available at: www.stopbullying.gov/ get-help-now/index.html. Accessed February 6, 2017

61. American Academy of Pediatrics. The Resilience Project. Available at: https:// www.aap.org/en-us/advocacy-andpolicy/aap-health-initiatives/resilience/ Pages/default.aspx. Accessed February 6, 2017

62. American Medical Association. Physician resources for an LGBTQinclusive practice. Available at: https:// www.ama-assn.org/delivering-care/ physician-resources-lgbtq-inclusivepractice. Accessed February 6, 2017

63. Crenshaw K. Mapping the margins: intersectionality, identity politics, and violence against women of color. Stanford Law Rev. 1991;43(6):1241-1299

64. Cole ER. Intersectionality and research in psychology. Am Psychol. 2009;64(3):170-180

65. Rosenthal L. Incorporating intersectionality into psychology: an opportunity to promote social justice and equity. Am Psychol. 2016;71(6):474-485

66. Sanders JQ, Feit MN, Alper J. Collecting Sexual Orientation and Gender Identity 
Data in Electronic Health Records: Workshop Summary. Washington, DC: The National Academies Press; 2013

67. Cahill SR, Baker K, Deutsch MB, Keatley J, Makadon HJ. Inclusion of sexual orientation and gender identity in stage 3 meaningful use guidelines: a huge step forward for LGBT health. LGBT Health. 2016;3(2):100-102

68. Deutsch MB, Green J, Keatley J, Mayer G, Hastings J, Hall AM; World Professional Association for Transgender Health EMR Working Group. Electronic medical records and the transgender patient: recommendations from the World Professional Association for Transgender Health EMR Working Group. J Am Med Inform Assoc. 2013;20(4):700-703

69. Deutsch MB, Buchholz D. Electronic health records and transgender patients-practical recommendations for the collection of gender identity data. J Gen Intern Med. 2015;30(6):843-847

70. GLSEN. Inclusion and respect: GLSEN resources for educators website. Available at: www.glsen.org/educate/ resources. Accessed 0ctober 24 2016

71. Hollander G. Questioning youths: challenges to working with youths forming identities. School Psych Rev. 2000;29(2):173-179

72. Swearer SM, Turner RK, Givens JE, Pollack WS. "You're so gay!": do different forms of bullying matter for adolescent males? School Psych Rev. 2008;37(2):160-173

73. Chaney KE, Sanchez DT, Remedios JD. Organizational identity safety cue transfers. Pers Soc Psychol Bull. 2016;42(11):1564-1576 